\title{
Smart phone Fe test kit as quick screening tool for identification of high risk areas for arsenic exposure
}

\author{
D. Halem \& A. Mink \\ Watermanagement Department, Faculty of Civil Engineering and Geosciences, \\ Delft University of Technology, Delft, The Netherlands
}

\begin{abstract}
Arsenic contamination of reduced shallow aquifers, as in deltas around the world, including Bangladesh and India has been found to frequently co-occur with dissolved ferrous iron. In this study the deployment of smart phone $\mathrm{Fe}$ test kit for identification of arsenic-affected villages was found to be a powerful, quick screening instrument for problem mapping in areas dependent for their water supply on tubewell groundwater from arsenic-contaminated, reduced aquifers. The research consisted of laboratory investigation of smart phone test kit accuracy under different conditions (light, exposure time, smart phone brand) and a proof-of-concept field study by screening 365 tube-wells in a potentially arsenic-affected area in Bhojpur, Bihar (India).
\end{abstract}

\section{INTRODUCTION}

Mobile crowd participation is gaining interest in the field of water research as a novel tool for inclusion of end-users, a critical ingredient of sustainable water supply (Prahalad, 2012; Wilkinson et al., 2014). Smart phone water quality test kits (Akvo.org) could provide end-users an active role in water quality monitoring programs and raise awareness amongst rural communities. Smart phone coverage has rapidly increased the past years, particularly amongst the youth (GSMA, 2017, Mink et al., 2017).

Arsenic contamination of reduced shallow aquifers, as found in deltas around the world, including Bangladesh and India has been found to frequently co-occur with dissolved ferrous iron. Given the fact that arsenic analysis in the field is time-consuming and relatively expensive, it was the aim of this study to investigate the use of inexpensive $\mathrm{Fe}$ smartphone test kits as a quick screening tool for identification of high risk areas for arsenic occurrence. The research consisted of laboratory investigation of smart phone test kit accuracy under different conditions (light, exposure time, smart phone brand) and a proof-of-concept field study by screening 365 tubewells in a potentially arsenic-affected area in Bhojpur, Bihar (India).

\section{METHODS}

\subsection{Laboratory tests: smart phone test accuracy}

The Akvo Caddisfly and Akvo Flow app were both installed on different smart phones (including Samsung Galaxy J7) and used for the reading of HACH Fe test strip discoloration with a reference card (Fig. 1). $\mathrm{Fe}(\mathrm{II}) \mathrm{SO}_{4}$ solutions were prepared, ranging from

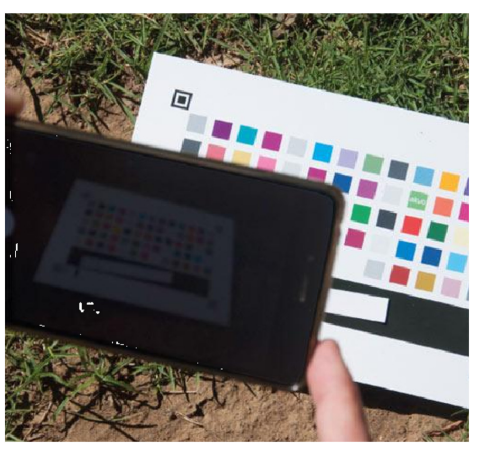

Figure 1. Smart phone and reference card (Akvo.org).

0.1-4 mg L ${ }^{-1}$. Pictures were taken directly upon finishing the test in natural sunlight and indoors; additionally, repetitive pictures were taken after 5 and 10 min exposure time.

\subsection{Proof-of-concept field study}

In Bhojpur, Bihar, 365 shallow tubewells were sampled for immediate analyses with smartphone Fe test kit. Subsequently $15 \mathrm{~mL}$ sample vials were transported to the laboratory for ICP-MS analyses (As and $\mathrm{Fe}$ ) after $0.45 \mu \mathrm{m}$ filtration and acidification with nitric acid.

\section{RESULTS AND DISCUSSION}

\subsection{Smart phone test kit accuracy}

Figure 2 depicts the $\mathrm{Fe}$ concentrations detected by the smart phone test kit in direct sunlight against the 


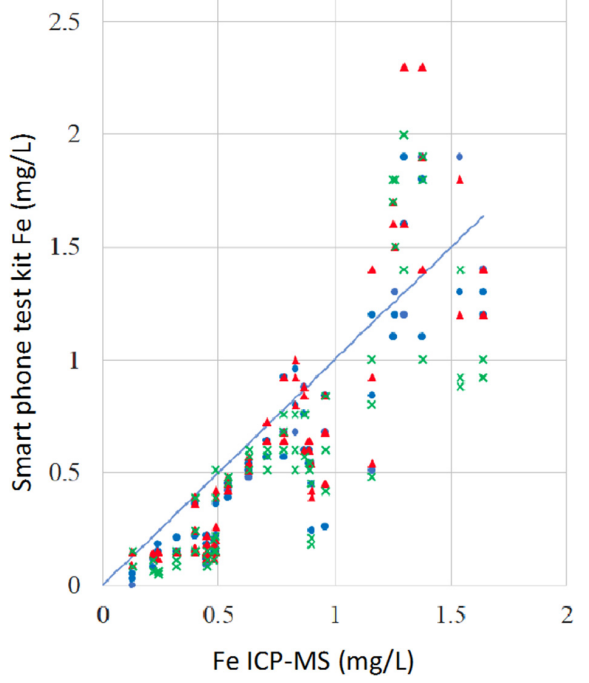

Figure 2. Smart phone test kit accuracy in direct sunlight.

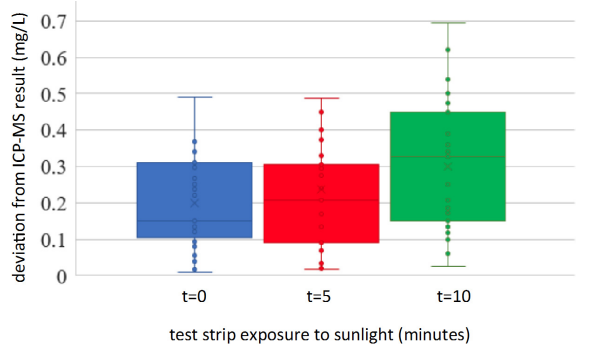

Figure 3. Effect of test strip sunlight exposure on documented Fe result.

values measured with ICP-MS. The test kit systematically underestimated the actual $\mathrm{Fe}$ concentrations, with increasing inaccuracy at higher concentrations $\left(>1 \mathrm{mg} \mathrm{L}^{-1}\right.$ ). The results were consistent, independent of mobile phone brand and lighting (results not shown). Only when test strips were not directly tested, the color of the strip faded with a consequently lower reading by the smart phone after $10 \mathrm{~min}$ (Fig. 3).

\section{$3.2 \mathrm{Fe}$-As co-occurrence in Bhojpur}

The ICP-MS results for Fe and As from 365 tubewell samples from Bhojpur, showed that all tubewells with As concentrations $>50 \mu \mathrm{g} \mathrm{L}^{-1}$ contained Fe concentrations $>1 \mathrm{mg} \mathrm{L}^{-1}$ (results not shown). The test kit Fe results showed some outliers, but altogether the results are alike - except for the test kit detection limit beyond $5 \mathrm{mg} \mathrm{L}^{-1}$. Based on this As-Fe relationship, it may be concluded that $>50 \mathrm{As}_{\mu \mathrm{gL}^{-1}}$ tubewells can be identified with the smart phone Fe test kit. Identification of $<10 \mu \mathrm{g} \mathrm{L}^{-1}$ tubewells (WHO guideline) was not achieved for all wells, as 21 tubewells had Fe concentrations $<1 \mathrm{mg} \mathrm{L}^{-1}$, but As concentrations between 10 and $50 \mu \mathrm{gL}^{-1}$. It should be noted, though, that the smart phone test kit is only considered a powerful tool

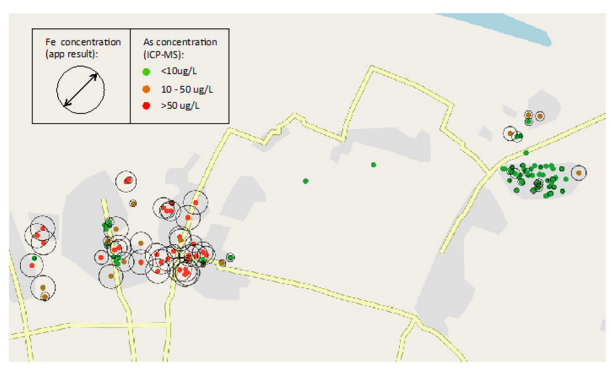

Figure 4. As (ICP-MS) and Fe (smart phone test kit) results for two neighboring villages in Bihar, India.

when "crowd" data are collected - providing a high density of data points and with that a higher accuracy towards detection of high-risk areas.

\subsection{Smart phone results as screening tool}

Figure 4 depicts the GPS-stamped data collected with the smart phone Fe test kit (black circles) together with the ICP-MS results for As (colored dots). The smart phone Fe test kit results clearly show the elevated $\mathrm{Fe}$ concentrations in the western village, compared to the eastern village. This finding is in agreement with the ICP-MS measurements for As, showing that that the smart phone Fe test kit functions as a quick screening tool for high risk As villages in Bhojpur. This finding is supported by measurements in four surrounding villages; and will be further investigated in arsenicaffected areas with similar geochemical settings.

\section{CONCLUSIONS}

In this study the deployment of smart phone $\mathrm{Fe}$ test kit for identification of arsenic-affected villages was found to be a powerful, quick screening instrument for problem mapping in areas dependent for their water supply on tubewell groundwater from arsenic-contaminated, reduced aquifers.

\section{ACKNOWLEDGEMENTS}

This research was funded through the "Urbanising Deltas of the World" programme of NWO WOTRO Science for Global Development.

\section{REFERENCES}

Akvo Foundation, www.akvo.org.

Gsma 2017 Economic Impact: Bangladesh Mobile Industry. Groupe Speciale Mobile Association, 7.

Mink, A., Hoque, B., \& van Halem, D. 2017. Mobile Crowd Participation, IWA Water and Development Congress, Argentina.

Prahalad, C. 2012 Bottom of the pyramid as a source of breakthrough innovations. J. Product. Innov. Man. 29: 6-12.

Wilkinson, C.R., \& De Angeli, A., 2014. Applying user centred and participatory design approaches to commercial product development. Design Studies 35: 614-631. 